\title{
The Glucosamine Controversy; A Pharmacokinetic Issue
}

\author{
Ali Aghazadeh-Habashi, Fakhreddin Jamali
}

Faculty of Pharmacy and Pharmaceutical Sciences, University of Alberta, Edmonton, Canada.

Received, May 9, 2011; Revised, June 21, 2011; Accepted June 23, 2011; Published, June 27, 2011.

\begin{abstract}
Glucosamine (GlcN) is a naturally occurring aminosugar that is widely used to treat osteoarthritis despite controversial clinical trial results. Animal studies, on the other hand, unequivocally suggest antiinflammatory and disease modifying effects for GlcN. Many explanations have been offered as to the root of the controversy. They include superiority of a crystalline sulphate salt over $\mathrm{HCl}$, industry bias, insensitive assessment metrics and poor methodology. Herein, we rule out a difference in bioequivalence between GlcN salts and that of chemically equivalent doses and suggest additional factors; i.e., inconsistency in the chemical potency of some products used, under-dosing of patients as well as variable and erratic bioavailability indices for the lack of GlcN efficacy observed in some studies. Clinical trials using higher doses of pharmaceutical grade GlcN or formulations with greater bioavailability should yield positive results.
\end{abstract}

This article is open to POST-PUBLICATION REVIEW. Registered readers (see "For Readers") may comment by clicking on ABSTRACT on the issue's contents page.

\section{CONTENTS: \\ - Background \\ - Evidence for and against the beneficial effects of glucosamine \\ - Potential Sources of controversy \\ - Inconsistency of commercial products and its consequence on clinical trial outcomes \\ - Dose-effect relationship and bioequivalence \\ - Therapeutic outcome measurements \\ - Conclusion}

Glucosamine (GlcN), a naturally occurring aminosugar, is widely used to treat osteoarthritis (OA). Regardless of continuous debate on its effectiveness, it is popular among patients as its global sale of $>\$ 2$ billion in 2009 attests (1). Several studies suggest that GlcN modifies the symptom of $\mathrm{OA}$ and halts the disease progression with a favourable safety profile $(2,3)$. Similarly, animal studies strongly suggest disease-modifying effects and anti-inflammatory properties (Table 1). However, the compound remains, perhaps, the most misunderstood therapeutic agent in use. While some reports suggest beneficial effects, other clinical trials and subsequent meta-analyses are inconclusive with their results ranging from strongly effective to negligible or no benefit to patient (4-12).

This article is presented in an attempt to shed new light onto the reasons for the controversy surrounding the issue of beneficial effects of GlcN. Since two thoughtful reviews on the topic have appeared since $2009(13,14)$, we will briefly mention the source of controversy and will focus on new issues.

\section{Evidence for and against the beneficial effects of glucosamine}

In general, animal and in vitro studies have focused on the effect of GlcN on damaged joints and particularly on the site-specific beneficial effects (Table 1). Although results of such studies are often difficult to extrapolate to beneficial effects in humans, it appears that, indeed, GlcN does positively influence the biology of damaged issues. These studies ascribe anti-inflammatory properties to GlcN through inhibition of various pro-inflammatory mediators such as nitric oxide, cyclooxygenase-2 (COX-2), matrix metalloproteinases (MMP) but mainly in the context of OA (15-27). In addition to these mainly site specific studied, Hua et al (28), have reported the inhibitory effect of $\mathrm{GlcN}$ on the emergence of adjuvant arthritis (AA) in the rat (29).

They have shown that daily administration of GlcN commencing on the day of adjuvant injection to induce AA, inhibits the emergence of the disease. AA is a type of severe arthritis that influences all joints and is associated with various systemic signs and symptoms. AA is often considered as a model for rheumatoid arthritis (RA).

Corresponding author: F. Jamali, Faculty of Pharmacy \& Pharmaceutical Sciences, University of Alberta, Edmonton, Alberta, Canada T6G 2N8; fjamali@pharmacy.ualberta.ca 


\begin{tabular}{|c|c|c|c|c|c|}
\hline Animal & Salt & Dose, $\mathrm{mg} / \mathrm{kg} /$ day & Duration, weeks & Outcome & Reference \\
\hline Rabbit (OA) & $\mathrm{HCl}$ & 27 & 8 & $\begin{array}{l}\text { Detectable, site-specific, partial disease- } \\
\text { modifying effect }\end{array}$ & $(30)$ \\
\hline Rabbit (OA) & $\mathrm{HCl}$ & 20 and 100 & 8 & $\begin{array}{l}\text { Dose-dependent increase of glycosaminoglycan } \\
\text { content in contralateral knee }\end{array}$ & $(31)$ \\
\hline Rabbit (OA) & $\mathrm{HCl}$ & 100 & 8 & $\begin{array}{l}\text { Improved subchondral bone turnover, structure, } \\
\text { and mineralization }\end{array}$ & $(32)$ \\
\hline Rabbit (OA) & $\begin{array}{l}\text { Sulfate } \\
\text { or } \mathrm{HCl}\end{array}$ & $800-1000$ & 8 & Chondroprotective effect; reduced MMP-1 & (34) \\
\hline Rat (OA) & $\mathrm{HCl}$ & 1000 & 8 & $\begin{array}{l}\text { Chondroprotective by inhibiting degradation and } \\
\text { enhancing synthesis of type II collagen }\end{array}$ & $(35)$ \\
\hline Rat (AA) & $\mathrm{HCl}$ & 300 & 3 & Suppress progression of adjuvant arthritis & $(28)$ \\
\hline
\end{tabular}

Despite the overwhelming evidence generated using experimental animals in favour of beneficial effects for GlcN in the treatment of arthritis, randomized human clinical trials are not conclusive as some have observed benefit for both pain and joint function (e.g., 2,36) and others have seen no or negligible positive effects (e.g., 37,38). Similarly, subsequent meta-analysis and systemic reviews that included the original reports were not quite in agreement (39). To the best of our knowledge, the latest meta-analysis is that of Wandel et al that has pulled together data from both $\mathrm{GlcN}$ alone and various combinations of $\mathrm{GlcN}$ and chondroitin (6). The authors did not find any beneficial effect for the treatments. They were later criticised for the study design and criteria used by two groups of authors who had conducted industrysponsored clinical trials on GlcN with positive results $(40,41)$.

Among the reported clinical trials a few have attracted considerable attention. They include the studies that were typically sponsored by the European producer of glucosamine crystalline sulfate (GlcN-S, Rottapharm, S.p.A., Monza Italy) that typically demonstrated positive results (e.g., 42-45). The other highly publicized trial is the independent Glucosamine/chondroitin Arthritis Intervention Trial (GAIT) (37). This study tested the effectiveness of GlcN $\mathrm{HCl}$ alone and in combination with chondroitin and concluded that none of the treatments were superior to placebo in pain relief but suggested beneficial effects of the combination is a prespecified group with severe knee pain. Previously a Cochrane Collaboration review of clinical trials conducted on GlcN (39) had also concluded that "Pooled results from studies using a non-Rotta preparation or adequate allocation concealment failed to show benefit in pain and WOMAC function while those studies evaluating the Rotta preparation showed that glucosamine was superior to placebo in the treatment of pain and functional impairment resulting from symptomatic OA." WOMAC is a selfadministered knee and hip osteoarthritis index.To make the matter even more complicated 2 two-year follow-up reports of a cohort of patients enlisted in GAIT have detected no significant difference between the groups treated with $\mathrm{GlcN} \mathrm{HCl}$, celecoxib or placebo $(8,46)$. This is when other studies have suggested effectiveness for celecoxib in the treatment of OA (47). The observed lack of superiority over placebo of two years of treatment with GlcN and celecoxib is attributed to a low baseline level of pain that can render the treatment effect difficult to assess, and also as the placebo group demonstrated improvement, to the very high expectation bias on the part of 2 years of treatment (46). The authors suggest re-evaluation of the assessment factors involved is designing future OA trials. Interestingly, despite the publicity around the negative results of the GAIT study, GlcN has maintained its popularity among OA patients $(1,48)$.

\section{Potential Sources of controversy}

\section{Inconsistency of commercial products and its consequence on clinical trial outcomes}

We have previously shown that, at least for the Canadian products, 13 out of 14 tested formulations contained substantially lower than label claims of the active ingredient (Table 2) (49). This is mainly due to the physical instability of GlcN crystals that is 
overcome with co-crystallization with $\mathrm{KCl}$. The crystals of the active ingredient, therefore, are diluted with $\mathrm{KCl}$. Except for the European Union, where GlcN is regulated as a pharmaceutical, the quality control of the commercially available products of GlcN has been a prerogative of the manufacturer, hence, it might have used the diluted crystals without allowance given for the co-crystalization.

A typical clinical trial report has either no mention of the validity of the label-claim of the product used or contains only a statement conveying the manufacturer's claim with no assurance indicating an actual dose-potency measurement. While the formulation used in the GAIT study (37) is reported to be tested for its active ingredient content, for the studies included in the meta-analysis of Wandel et al (6) assurances from the manufacturers appear to be deemed sufficient as a measure of the products chemical potency (e.g., 50,51). It is, therefore, reasonable to suggest that the patients in some of the reported clinical trials may have been under-dosed.

It is important to note that the results of some of the GlcN clinical trials with negative outcomes do not totally rule out potential benefits or trend toward efficacy of the treatment in some patients $(8,37,46,51)$. This, coupled with the possibility of under-dosing with the less than claimed $1500 \mathrm{mg}$ /day regimens, highlight the need for clinical trials using higher pharmaceutical grade GlcN doses or formulations that yield greater plasma concentrations.

\section{Dose-effect relationship and bioequivalence}

Almost all of the human clinical trials are carried out with a dosage regimen of 1500/day. Interestingly, at certain stage, investigators should have known that such a dosage regimen was going to yield concentration substantially lower than those used in in vitro or in animal studies $(13,27,52)$. Also, the positive trend toward GlcN's beneficial effect reported by several authors $(8,37,46,51)$ should have alarmed them of the possibility of under-dosing. Nevertheless, to the best of our knowledge, no attempt was made to test a higher dosage regimen even by the investigators involved in the GAIT study who used a pharmaceutical grade formulation. The physical size of glucosamine products (e.g., $1.4 \mathrm{~g}$ for a $500 \mathrm{mg}$ tablet) might have been, at least in part, a deterrent for using higher dose levels.

It is well-known that most reported animal data on the pharmacological properties of GlcN are generated following high doses. However, the minimum effective dose, hence, minimum effective concentration of GlcN in animals has remained unknown. Consequently, the gap between plasma GlcN concentration in human and that associated with effectiveness in experimental animals is unknown. The available human pharmacokinetic data demonstrate great inter-study variations (Table 3). The reported peak concentration following a $1500 \mathrm{mg}$ dose ranges from 0.492 to $3.36 \mathrm{mg} / \mathrm{L}$; i.e., a 6-fold

\begin{tabular}{|c|c|c|c|c|c|c|}
\hline 1 & $\mathrm{~T}$ & 500 & $\mathrm{~S}+\mathrm{C}$ & 542 & 688 & 108 \\
\hline 3 & $\mathrm{C}$ & 500 & $\mathrm{~S}$ & 277 & 351 & 55 \\
\hline 4 & $\mathrm{C}$ & 500 & S & 325 & 445 & 65 \\
\hline 7 & $\mathrm{~T}$ & 1500 & S & 634 & 804 & 42 \\
\hline 8 & $\mathrm{C}$ & 500 & S & 233 & 295 & 41 \\
\hline 9 & $\mathrm{C}$ & 500 & S & 298 & 378 & 60 \\
\hline 10 & $\mathrm{C}$ & 500 & $\mathrm{~S}$ & 231 & 293 & 46 \\
\hline 11 & $\mathrm{C}$ & 500 & S & 274 & 348 & 55 \\
\hline
\end{tabular}

Adopted from Ref (49). 


\begin{tabular}{|c|c|c|c|c|c|}
\hline \multirow[t]{2}{*}{ Dose, mg } & \multicolumn{2}{|c|}{ Cmax } & $\mathrm{AUC}_{0-\mathrm{t}}$ & $\mathrm{AUC}_{0-\infty}$ & \multirow[t]{2}{*}{ Reference } \\
\hline & $\mathrm{mg} / \mathrm{L}$ & $\mu \mathrm{M}$ & mg.h/L & & \\
\hline 1500 & $3.11 \pm 2.2$ & $17.4 \pm 11.96$ & $9.85 \pm 4.1(8 h)^{f}$ & $10.3 \pm 4.1$ & (53) \\
\hline $500^{\mathrm{a}}$ & $1.11 \pm 0.51$ & $6.2 \pm 2.85$ & $5.25 \pm 2.16(14 \mathrm{~h})^{\mathrm{f}}$ & $5.31 \pm 2.16$ & (54) \\
\hline $500^{\mathrm{a}}$ & $3.36^{\mathrm{b}}$ & $19.0^{\mathrm{b}}$ & $\mathrm{NR}$ & $19.7^{\mathrm{b}}$ & (55) \\
\hline 1500 & $1.60 \pm 0.42$ & $8.95 \pm 2.37$ & $20.22 \pm 5.02(48 \mathrm{~h})^{\mathrm{f}}$ & $14.6 \pm 4.14$ & (56) \\
\hline $1500^{\mathbf{c}}$ & $0.492 \pm 0.16$ & $2.75 \pm 0.9$ & NR & $2.38 \pm 0.94$ & (57) \\
\hline 1500 & $0.90 \pm 0.43^{\mathrm{d}}$ & $5.04 \pm 2.4^{\mathrm{d}}$ & NR & NR & (52) \\
\hline
\end{tabular}

a, indices were calculated for $1500 \mathrm{mg}$ doses; b, geometric means, hence, no SD; all sulphate except ' $\mathrm{c}$ '; all value at steady state except ' $d$ '; f, the value in bracket indicate the time for the last measured concentration; NR, not reported.

difference between the highest (GlcN crystalline sulphate) and the lowest ( $\mathrm{GlcN} \mathrm{HCl}$ as used in GAIT). This brings up an important question: Is the source of the discrepancy between the outcomes of various clinical trials a difference in GlcN bioavailability from different formulations?

Although the values listed in Table 3 are from different studies, hence, are not generated according to a cross-over or simultaneous parallel fashion, the fact that the human exposure to GlcN following ingestion of the HCL salt used in the GAIT study (57) is so much lower than that of the sulphate salt (Table 3) raises a good question that we cannot address. It is intuitively accepted that following ingestion and subsequent dissolution in the gut, both sulfate and $\mathrm{HCl}$ salts of $\mathrm{GlcN}$ are immediately ionized to glucosamine, hence, the nature of the salt becomes irrelevant. If so, the differences between the two products should be at the level of formulation and not the nature of the salt.

To assess the effect of the salt nature on the bioavailability of GlcN, we present a preliminary set of data generated following a random cross-over oral gavage to the of equal doses (equivalent to $100 \mathrm{mg} / \mathrm{kg}$ GlcN base grinded and suspended in PEG 400) of $\mathrm{HCl}$ (Sigma-Aldrich Canada, LTD, Oakville, ON) as used in the GIAT trial [Personal communication with J.D. Sandy(57)] or the crystalline sulfate (Dona, Lot No. PR 24080004, RottaPhram, Monza, Italy, purchased from a community pharmacy in Florence, Italy). We have previously reported the dosing and sampling methods $(58,59)$ as well as the assay $(59)$ used.

No significant difference in bioavailability indices was observed between the two formulations (Fig 1, Table 4). This cross-over assessment unequivocally proves that the nature of the salt does not influence the bioavailability of GlcN administered orally.
The rat data presented herein confirm a previous observation that, in horses, $\mathrm{GlcN} \mathrm{HCl}$ and sulfate are bioequivalent (60) but does not rule out the effect of formulation per se. We therefore, designed a brief open-label cross-over bioavailability study in healthy volunteers to directly compare GlcN$\mathrm{HCl}$ as used in the GAIT study with a Rottapharm product. We used the urinary excretion data for comparison as, despite the limited excretion of intact GlcN, it has been found to be a reliable and less variable measure of the pharmacokinetic indices of GlcN (61).

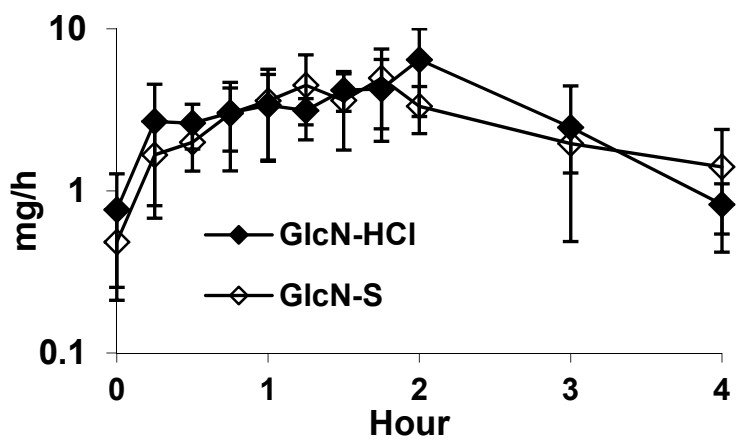

Figure 1. Glucosamine plasma concentration vs time after oral administration of $100 \mathrm{mg} / \mathrm{kg}$ as $\mathrm{HCl}$ or sulfate salts into the rat. GlcN plasma concentrations were measured according to a previously described method (59). Formulations were grinded and suspended in polyethylene glycol 400 before administration. Their potency measured by HPLC (62) was $99.9 \%$ for the $\mathrm{HCl}$ and $95.2 \%$ for the sulfate. Concentrations in zero $\mathrm{h}$ samples demonstrate endogenous GlcN. Male Sprague-Dawley rats (300-360 g; $\mathrm{n}=5$ /group) were dosed through a gastric gavage after an overnight food deprivation but free access to water. Blood samples were collected over a $4 \mathrm{~h}$ post-dose period, plasma separated and stored at $-20^{\circ} \mathrm{C}$ until analyzed for GlcN. 
Table 4. GlcN Pharmacokinetic indices following cross-over oral administration of single $100 \mathrm{mg}$ doses of the compound as $\mathrm{HCl}$ or crystalline sulfate to 5 rats.

\begin{tabular}{lcc}
\hline Parameters & GlcN-HCl & GlcN-S \\
\hline $\mathrm{t}_{\max }, \mathrm{h}$ & $1.50 \pm 0.73$ & $1.30 \pm 0.33$ \\
$\mathrm{C}_{\max }, \mathrm{mg} / \mathrm{L}$ & $7.49 \pm 2.76$ & $7.92 \pm 1.84$ \\
$90 \%$ Confident interval & & 94.9 \\
of geometric means, \% & & $(80.9 \%-109.0)$ \\
$\mathrm{AUC} \mathrm{t}_{\mathrm{t}} \mathrm{mg} . \mathrm{h} / \mathrm{L}$ & $13.59 \pm 3.64$ & $10.12 \pm 2.54$ \\
$90 \%$ Confident interval & & 112.4 \\
of geometric means, \% & $(100.4 \%-124.4)$ \\
\hline \multicolumn{2}{l}{ Data are presented as mean $\pm \mathrm{SD}$ (n=5/group). } \\
\hline
\end{tabular}

Four healthy volunteers (1female and 3 males, $47 \pm 12.5 \mathrm{yr}, 81.8 \pm 11.6 \mathrm{~kg}, 177 \pm 7 \mathrm{~cm})$ took $1500 \mathrm{mg}$ GlcN crystalline sulphate (Dona, $250 \mathrm{mg}$ tablets Lot No. PR 24080004, RottaPhram, Monza, Italy) or its equivalent of GlcN HCl (Sigma-Aldrich Canada, LTD, Oakville, ON) dispensed in capsules as used in GIAT. They took the formulations after an overnight fast with $250 \mathrm{~mL}$ water in a random fashion with a 2 week washout period. GlcN was measured in total urine output and the total and rate of excretion measured for $13 \mathrm{~h}$ post-dose using HPLC (59). No significant differences were found between the two products in either urinary excretion rate plots (Figure 2 ) or in the total amount excreted (Table 5). This cross-over study suggests that the formulations used in the GAIT study and those reported for GlcN crystalline sulfate are bioequivalent and rules out the effect the effect of formulation differences between the two products.

Our data are preliminary and, perhaps, need to be confirmed with a more details study. Nevertheless, the rat and human data on the bioequivalence of $\mathrm{GlcN}$ salts and formulations strongly suggest that the $\mathrm{HCl}$ formulation used in GAIT and the commercially available Rottapharm tablets, indeed, yield equal body exposure to the compound. The discrepancy in the reported pharmacokinetic indices in general and the relatively low concentration of the formulation used in the GAIT study in particular, needs further attention.

It is known that inflammatory conditions may inhibit clearance of drugs that efficiently undergo hepatic metabolism (i.e., first pass effect) (64-66). There are two reasons to rule out this possibility for the present case: i) there is no evidence of efficient hepatic metabolism for GlcN as its low bioavailability appears to be due to its loss in the gut (58) and ii) except for one (52), all studies have been carried out in normal volunteers indicating a great variation in healthy state.
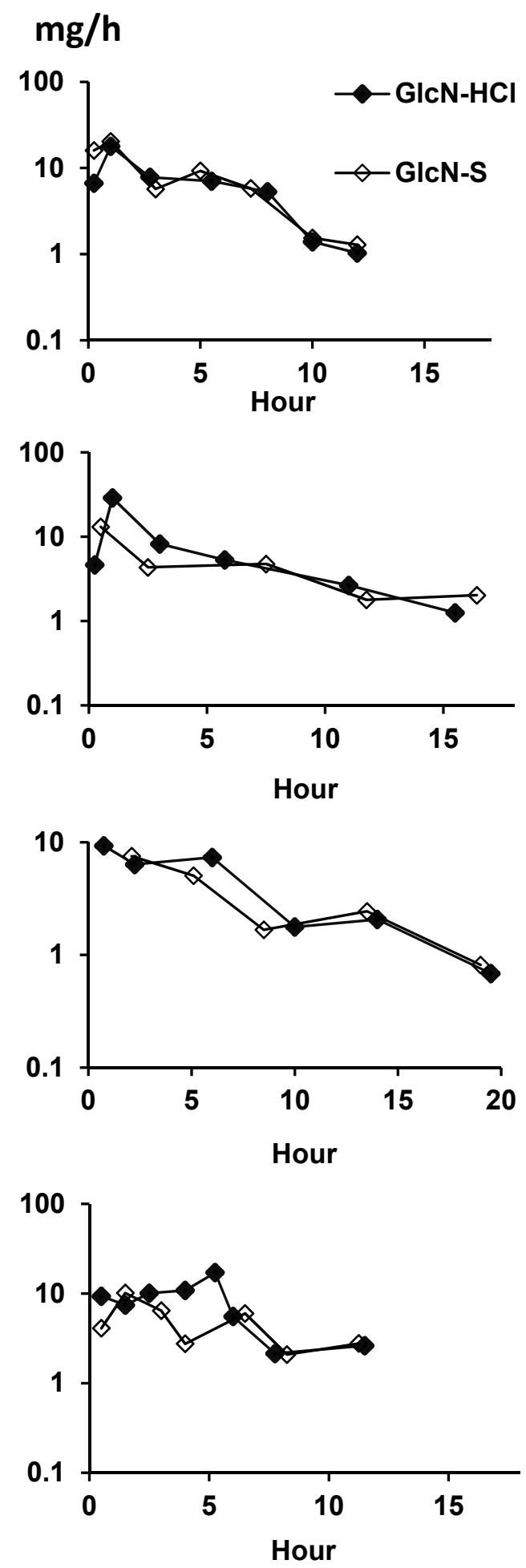

Figure 2. Glucosamine urinary excretion rate vs mid time point of urine collection period following single oral dose of $1500 \mathrm{mg}$ GlcN crystalline sulfate or its equivalent $\mathrm{HCl}$ salt to humans. Each graph represents one individual. 


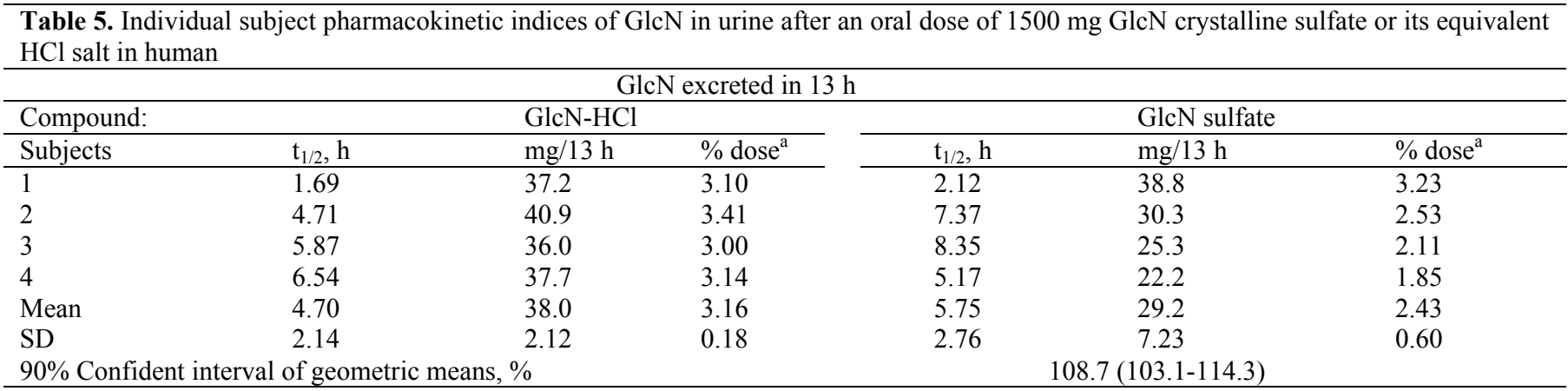

a, calculated based on $26 \%$ absolute bioavailability of radiolabelled GlcN (63)

Some authors have suggested industry bias as one of the sources of the differences between the two sides of the debate (12). Such a notion, however, does not address the issue of plasma concentration differences between the two formulations. Among the sets of data reported thus far, those of Jackson et al (i.e., the $\mathrm{HCl}$ formulation used in GAIT) stands out for its substantially lower peak plasma concentration $(0.49 \mathrm{mg} / \mathrm{L})$. Since other studies with peak concentrations range of 0.9 to $3.36 \mathrm{mg} / \mathrm{L}$ are not all sponsored by a single industry source, it is reasonable to rule out the possibility of an industry bias for the reported pharmacokinetic data. Hence, the question remains as to the reason for such a low bioavailability for the GAIT formulation and the possibility of a link between the negative beneficial effects of the latter. This is particularly important since several authors have suggested a concentration dependent-effect for GlcN $(13,27)$. For example, it has been suggested that for the long-term protection of cartilage to stimulated aggrecan loss in osteoarthritis continual presence of $\mathrm{GlcN}$ in plasma is required (67).

Based on in vitro and animal data, several investigators have pointed out the need for higher concentration in human studies to reach therapeutic levels $(13,14,27,68)$. Repeated $300 \mathrm{mg} / \mathrm{kg}$ dose of GlcN to the rat completely inhibit emergence of adjuvant arthritis (28). Such a regimen should yield a peak plasma concentration of approximately $16 \mathrm{mg} / \mathrm{L}$ [Aghazedeh et al (58) reported a peak concentration of $18.8 \mathrm{mg} / \mathrm{L}$ following a single $350 \mathrm{mg} / \mathrm{kg}$ dose] which is much greater than those reported following $1500 \mathrm{mg} / \mathrm{kg}$ doses to humans (Table 3). The 300 $\mathrm{mg} / \mathrm{kg}$ regimen, however, is not necessarily the minimum effect dose (Table 1). This should prompt investigators to assess GlcN efficacy following higher doses of GlcN or formulations with improved bioavailability.

\section{Therapeutic outcome measurements}

In assessing the effectiveness of $\mathrm{GlcN}$ in $\mathrm{OA}$, double blind placebo-controlled methods are used. The outcome measurement includes various measures such as WOMAC arthritis index which is a selfadministered knee and hip assessment, various pain scales, radiographic techniques and joint space narrowing. The sensitivity of these methods to differentiate between treatments may be questioned. Indeed, some investigators who were following GlcN effects in a sub group of patients enrolled in the GAIT study have not even been able to differentiate between a non-controversial treatment (celecoxib) (46) and placebo so that they suggested a reevaluation of the assessment factors involved is designing future $\mathrm{OA}$ trials. Interestingly, these authors attribute the observed lack of superiority over placebo of the two year treatment with GlcN and celecoxib to the possibility of a low baseline level of pain and a placebo effect due to a very high expectation bias on the part of 2 years of treatment (46). If so, the same must be applied to other clinical trials as well and, indeed, gives more credence to the issue of heterogeneity across studies (12). With such assessment difficulties in place, the possibility of detecting moderate beneficial effects on mild to moderate $\mathrm{OA}$ is expected to be remote. This is, perhaps, why patients ignore the results of the scientific studies and continue using GlcN. It may be that some but not all patients do benefit from the treatment. 


\section{CONCLUSION}

GlcN has anti-inflammatory properties that are evident only upon administration to experimental animals of high doses or, perhaps, after dosing with formulations with high bioavailability. The discrepancy between the reported human clinical data is not due the nature of the salt or formulation properties. Regardless of the formulation used, following the commonly used $1500 \mathrm{mg} /$ day doses, no or marginal beneficial effects may be observed because of under-dosing which stems from low GlcN bioavailability and inconsistency in chemical potency of some commercially available products. Limited and erratic bioavailability of GlcN may also contribute to the problem. In addition, insensitive clinical outcomes and inclusion of patients with low baseline pain might have contributed to the unsatisfactory treatment outcome.

The source of the controversy in the efficacy of GlcN seems to be pharmacokinetic in nature as it is generally agreed that the available $\mathrm{GlcN}$ formulations yield sub-therapeutic plasma concentrations. At this stage there is an obvious need to determine the minimum effective GlcN dose and/or concentration and conduct clinical trials following higher doses of $\mathrm{GlcN}$ or formulations with improved bioavailability.

\section{REFERENCE}

1. Byrne J. Glucosamine market reaching maturity 5Apr-2010; $\quad$ http://www.nutraingredientsusa.com/Industry/Glucosamine-market-reachingmaturity, 2010.

2. Tat SK, Pelletier JP, Verges J, Lajeunesse D, Montell E, Fahmi $\mathrm{H}$, et al. Chondroitin and glucosamine sulfate in combination decrease the pro-resorptive properties of human osteoarthritis subchondral bone osteoblasts: a basic science study. Arthritis Res Ther 2007;9(6):R117.

3. Bruyere O, Reginster JY. Glucosamine and chondroitin sulfate as therapeutic agents for knee and hip osteoarthritis. Drugs Aging 2007;24(7):57380 .

4. Richy F, Bruyere $\mathrm{O}$, Ethgen $\mathrm{O}$, Cucherat $\mathrm{M}$, Henrotin Y, Reginster JY. Structural and symptomatic efficacy of glucosamine and chondroitin in knee osteoarthritis: a comprehensive meta-analysis. Arch Intern Med 2003 Jul 14;163(13):1514-22.

5. Towheed TE, Anastassiades T. Glucosamine therapy for osteoarthritis: an update. J Rheumatol 2007 Sep;34(9):1787-1790.
6. Wandel S, Juni P, Tendal B, Nuesch E, Villiger PM, Welton NJ, et al. Effects of glucosamine, chondroitin, or placebo in patients with osteoarthritis of hip or knee: network meta-analysis. BMJ 2010 Sep 16;341:c4675.

7. Bruyere O, Pavelka K, Rovati LC, Gatterova J, Giacovelli G, Olejarova $\mathrm{M}$, et al. Total joint replacement after glucosamine sulphate treatment in knee osteoarthritis: results of a mean 8-year observation of patients from two previous 3-year, randomised, placebo-controlled trials. Osteoarthritis Cartilage 2008 Feb;16(2).:254-60.

8. Sawitzke AD, Shi H, Finco MF, Dunlop DD, Bingham CO,3rd, Harris CL, et al. The effect of glucosamine and/or chondroitin sulfate on the progression of knee osteoarthritis: a report from the glucosamine/chondroitin arthritis intervention trial. Arthritis Rheum 2008 Oct;58(10):3183-91.

9. Hughes R, Carr A. A randomized, double-blind, placebo-controlled trial of glucosamine sulphate as an analgesic in osteoarthritis of the knee. Rheumatology (Oxford) 2002 Mar;41(3):279-284.

10. Cibere J, Thorne A, Kopec JA, Singer J, Canvin J, Robinson DB, et al. Glucosamine sulfate and cartilage type II collagen degradation in patients with knee osteoarthritis: randomized discontinuation trial results employing biomarkers. J Rheumatol 2005 May;32(5):896-902.

11. Cibere J, Kopec JA, Thorne A, Singer J, Canvin J, Robinson DB, et al. Randomized, double-blind, placebo-controlled glucosamine discontinuation trial in knee osteoarthritis. Arthritis Rheum 2004 Oct 15;51(5):738-745.

12. Vlad SC, LaValley MP, McAlindon TE, Felson DT. Glucosamine for pain in osteoarthritis: why do trial results differ? Arthritis Rheum 2007 Jul;56(7):226777.

13. Block JA, Oegema TR, Sandy JD, Plaas A. The effects of oral glucosamine on joint health: is a change in research approach needed? Osteoarthritis Cartilage 2010; 18:5-11.

14. Miller KL, Clegg DO. Glucosamine and chondroitin sulfate. Rheum Dis Clin North Am 2011 Feb;37(1):103-118.

15. Lin YC, Liang YC, Sheu MT, Lin YC, Hsieh MS, Chen TF, et al. Chondroprotective effects of glucosamine involving the p38 MAPK and Akt signaling pathways. Rheumatol Int 2008 Aug;28(10):1009-1016.

16. Kim MM, Mendis E, Rajapakse N, Kim SK. Glucosamine sulfate promotes osteoblastic differentiation of MG-63 cells via anti-inflammatory effect. Bioorg Med Chem Lett 2007 Apr 1;17(7):1938-42.

17. Mendis E, Kim MM, Rajapakse N, Kim SK. The inhibitory mechanism of a novel cationic glucosamine derivative against MMP-2 and MMP-9 
expressions. Bioorg Med Chem Lett 2009 May 15;19(10):2755-2759.

18. Rajapakse N, Kim MM, Mendis E, Kim SK. Inhibition of free radical-mediated oxidation of cellular biomolecules by carboxylated chitooligosaccharides. Bioorg Med Chem 2007 Jan 15;15(2):997-1003.

19. Rajapakse N, Mendis E, Kim MM, Kim SK. Sulfated glucosamine inhibits MMP-2 and MMP-9 expressions in human fibrosarcoma cells. Bioorg Med Chem 2007 Jul 15;15(14):4891-4896.

20. Hong H, Park YK, Choi MS, Ryu NH, Song DK, Suh SI, et al. Differential down-regulation of COX2 and MMP-13 in human skin fibroblasts by glucosamine-hydrochloride. J Dermatol Sci 2009 Oct;56(1):43-50.

21. Rafi MM, Yadav PN, Rossi AO. Glucosamine inhibits LPS-induced COX-2 and iNOS expression in mouse macrophage cells (RAW 264.7) by inhibition of p38-MAP kinase and transcription factor NF-kappaB. Mol Nutr Food Res 2007 May;51(5):587-593.

22. Chan PS, Caron JP, Orth MW. Effects of glucosamine and chondroitin sulfate on bovine cartilage explants under long-term culture conditions. Am J Vet Res 2007 Jul;68(7):709-715.

23. Neil KM, Orth MW, Coussens PM, Chan PS, Caron JP. Effects of glucosamine and chondroitin sulfate on mediators of osteoarthritis in cultured equine chondrocytes stimulated by use of recombinant equine interleukin-1beta. Am J Vet Res 2005 Nov;66(11):1861-1869.

24. Nakamura H, Shibakawa A, Tanaka M, Kato T, Nishioka K. Effects of glucosamine hydrochloride on the production of prostaglandin E2, nitric oxide and metalloproteases by chondrocytes and synoviocytes in osteoarthritis. Clin Exp Rheumatol 2004 May-Jun;22(3):293-299.

25. Largo R, Alvarez-Soria MA, Diez-Ortego I, Calvo E, Sanchez-Pernaute O, Egido J, et al. Glucosamine inhibits IL-1beta-induced NFkappaB activation in human osteoarthritic chondrocytes. Osteoarthritis Cartilage 2003 Apr;11(4):290-298.

26. Chang YH, Horng CT, Chen YH, Chen PL, Chen CL, Liang CM, et al. Inhibitory effects of glucosamine on endotoxin-induced uveitis in Lewis rats. Invest Ophthalmol Vis Sci 2008 Dec;49(12):5441-5449.

27. Ali AA, Lewis SM, Badgley HL, Allaben WT, Leakey JE. Oral glucosamine increases expression of transforming growth factor beta1 (TGFbeta1) and connective tissue growth factor (CTGF) mRNA in rat cartilage and kidney: Implications for human efficacy and toxicity. Arch Biochem Biophys 2011; 510:11-8.

28. Hua J, Suguro S, Hirano S, Sakamoto K, Nagaoka I. Preventive actions of a high dose of glucosamine on adjuvant arthritis in rats. Inflamm Res 2005 Mar;54(3):127-32.

29. Kim EY, Moudgil KD. The determinants of susceptibility/resistance to adjuvant arthritis in rats. Arthritis Res Ther 2009;11(4):239.

30. Tiraloche G, Girard C, Chouinard L, Sampalis J, Moquin L, Ionescu $\mathrm{M}$, et al. Effect of oral glucosamine on cartilage degradation in a rabbit model of osteoarthritis. Arthritis Rheum 2005 Apr;52(4):1118-1128.

31. Oegema TR,Jr, Deloria LB, Sandy JD, Hart DA. Effect of oral glucosamine on cartilage and meniscus in normal and chymopapain-injected knees of young rabbits. Arthritis Rheum 2002 Sep;46(9):2495-2503.

32. Wang SX, Laverty S, Dumitriu M, Plaas A, Grynpas MD. The effects of glucosamine hydrochloride on subchondral bone changes in an animal model of osteoarthritis. Arthritis Rheum 2007 May;56(5):1537-1548.

33. Wen ZH, Tang CC, Chang YC, Huang SY, Hsieh $\mathrm{SP}$, Lee $\mathrm{CH}$, et al. Glucosamine sulfate reduces experimental osteoarthritis and nociception in rats: association with changes of mitogen-activated protein kinase in chondrocytes. Osteoarthritis Cartilage 2010 Sep;18(9):1192-1202.

34. Kobayashi T, Notoya K, Nakamura A, Akimoto K. Fursultiamine, a vitamin B1 derivative, enhances chondroprotective effects of glucosamine hydrochloride and chondroitin sulfate in rabbit experimental osteoarthritis. Inflamm Res 2005 Jun;54(6):249-255.

35. Naito K, Watari $\mathrm{T}$, Furuhata A, Yomogida S, Sakamoto K, Kurosawa H, et al. Evaluation of the effect of glucosamine on an experimental rat osteoarthritis model. Life Sci 2010 Mar 27;86(1314):538-543.

36. Reginster JY, Richy F, Bruyere O. [Glucosamine as a pain-modifying drug in osteorthritis. What's new in 2006]. Rev Med Liege 2006 Mar;61(3):169-72.

37. Clegg DO, Reda DJ, Harris CL, Klein MA, O'Dell JR, Hooper MM, et al. Glucosamine, chondroitin sulfate, and the two in combination for painful knee osteoarthritis. N Engl J Med 2006 Feb 23;354(8):795-808.

38. McAlindon T, Formica M, LaValley M, Lehmer M, Kabbara K. Effectiveness of glucosamine for symptoms of knee osteoarthritis: results from an internet-based randomized double-blind controlled trial. Am J Med 2004 Nov 1;117(9):643-649.

39. Towheed TE, Maxwell L, Anastassiades TP, Shea B, Houpt J, Robinson V, et al. Glucosamine therapy for treating osteoarthritis. Cochrane Database Syst Rev 2005(2):CD002946.

40. Pelletier JP, Hochberg MC, du Souich P, Kahan A, Michel BA. Glucosamine and osteoarthritis. Effect size is encouraging. BMJ 2010 Nov 9;341:c6328. 
41. Giacovelli G, Rovati LC. Glucosamine and osteoarthritis. Conclusions not supported by methods and results. BMJ 2010 Nov 9;341:c6338.

42. Noack W, Fischer M, Forster KK, Rovati LC, Setnikar I. Glucosamine sulfate in osteoarthritis of the knee. Osteoarthritis Cartilage 1994 Mar;2(1):519.

43. Reginster JY, Deroisy R, Rovati LC, Lee RL, Lejeune E, Bruyere $\mathrm{O}$, et al. Long-term effects of glucosamine sulphate on osteoarthritis progression: a randomised, placebo-controlled clinical trial. Lancet 2001 Jan 27;357(9252):251-6.

44. Pavelka K, Gatterova J, Olejarova M, Machacek S, Giacovelli G, Rovati LC. Glucosamine sulfate use and delay of progression of knee osteoarthritis: a 3year, randomized, placebo-controlled, double-blind study. Arch Intern Med 2002 Oct 14;162(18):211323.

45. Herrero-Beaumont G, Ivorra JA, Del Carmen Trabado M, Blanco FJ, Benito P, Martin-Mola E, et al. Glucosamine sulfate in the treatment of knee osteoarthritis symptoms: a randomized, doubleblind, placebo-controlled study using acetaminophen as a side comparator. Arthritis Rheum 2007 Feb;56(2):555-567.

46. Sawitzke AD, Shi H, Finco MF, Dunlop DD, Harris CL, Singer NG, et al. Clinical efficacy and safety of glucosamine, chondroitin sulphate, their combination, celecoxib or placebo taken to treat osteoarthritis of the knee: 2-year results from GAIT. Ann Rheum Dis 2010 Aug;69(8):1459-1464.

47. Deeks JJ, Smith LA, Bradley MD. Efficacy, tolerability, and upper gastrointestinal safety of celecoxib for treatment of osteoarthritis and rheumatoid arthritis: systematic review of randomised controlled trials. BMJ 2002 Sep 21;325(7365):619.

48. Tilburt JC, Emanuel EJ, Miller FG. Does the evidence make a difference in consumer behavior? Sales of supplements before and after publication of negative research results. J Gen Intern Med 2008 Sep;23(9):1495-1498.

49. Russell AS, Aghazadeh-Habashi A, Jamali F. Active ingredient consistency of commercially available glucosamine sulfate products. J Rheumatol 2002 Nov;29(11):2407-9.

50. Rozendaal RM, Uitterlinden EJ, van Osch GJ, Garling EH, Willemsen SP, Ginai AZ, et al. Effect of glucosamine sulphate on joint space narrowing, pain and function in patients with hip osteoarthritis; subgroup analyses of a randomized controlled trial. Osteoarthritis Cartilage 2009 Apr;17(4):427-432.

51. Rozendaal RM, Koes BW, van Osch GJ, Uitterlinden EJ, Garling EH, Willemsen SP, et al. Effect of glucosamine sulfate on hip osteoarthritis: a randomized trial. Ann Intern Med 2008 Feb $19 ; 148(4): 268-277$.
52. Biggee BA, Blinn CM, McAlindon TE, Nuite M, Silbert JE. Low levels of human serum glucosamine after ingestion of glucosamine sulphate relative to capability for peripheral effectiveness. Ann Rheum Dis 2006 Feb;65(2):222-6.

53. Zhang LJ, Huang TM, Fang XL, Li XN, Wang QS, Zhang ZW, et al. Determination of glucosamine sulfate in human plasma by precolumn derivatization using high performance liquid chromatography with fluorescence detection: its application to a bioequivalence study. J Chromatogr B Analyt Technol Biomed Life Sci 2006 Sep 14;842(1):8-12.

54. Zhu Y, Zou J, Xiao D, Fan H, Yu C, Zhang J, et al. Bioequivalence of two formulations of glucosamine sulfate 500-mg capsules in healthy male Chinese volunteers: an open-label, randomized-sequence, single-dose, fasting, two-way crossover study. Clin Ther 2009 Jul;31(7):1551-1558.

55. Akarasereenont P, Chatsiricharoenkul S, Pongnarin P, Sathirakul K, Kongpatanakul S. Bioequivalence study of $500 \mathrm{mg}$ glucosamine sulfate in Thai healthy volunteers. J Med Assoc Thai 2009 Sep;92(9):12341239.

56. Persiani S, Roda E, Rovati LC, Locatelli M, Giacovelli G, Roda A. Glucosamine oral bioavailability and plasma pharmacokinetics after increasing doses of crystalline glucosamine sulfate in man. Osteoarthritis Cartilage 2005 Dec;13(12):1041-9.

57. Jackson CG, Plaas AH, Sandy JD, Hua C, KimRolands S, Barnhill JG, et al. The human pharmacokinetics of oral ingestion of glucosamine and chondroitin sulfate taken separately or in combination. Osteoarthritis Cartilage 2010 Mar;18(3):297-302.

(58. Aghazadeh-Habashi A, Sattari S, Pasutto F, Jamali F. Single dose pharmacokinetics and bioavailability of glucosamine in the rat. J Pharm Pharm Sci 2002 May-Aug;5(2):181-4.

59. Ibrahim A, Jamali F, Improved Sensitive High Performance Liquid Chromatography Assay for Glucosamine in Human and Rat Biological Samples with Fluorescence Detection. Journal of Pharmacy \& Pharmaceutical Sciences 2010;13(2):128.

60. Meulyzer M, Vachon P, Beaudry F, Vinardell T, Richard H, Beauchamp G, et al. Comparison of pharmacokinetics of glucosamine and synovial fluid levels following administration of glucosamine sulphate or glucosamine hydrochloride. Osteoarthritis Cartilage 2008 Sep;16(9):973-979.

61. Guan Y, Tian Y, Li Y, Yang Z, Jia Y, Hang T, et al. Application of a liquid chromatographic/tandem mass spectrometric method to a kinetic study of derivative glucosamine in healthy human urine. J Pharm Biomed Anal 2011 Apr 28;55(1):181-186. 
62. Aghazadeh-Habashi A, Sattari S, Pasutto F, Jamali F. High performance liquid chromatographic determination of glucosamine in rat plasma. J Pharm Pharm Sci 2002 May-Aug;5(2):176-80.

63. Setnikar I, Palumbo R, Canali S, Zanolo G. Pharmacokinetics of glucosamine in man. Arzneimittelforschung 1993 Oct;43(10):1109-13.

64. Emami J, Pasutto FM, Jamali F. Effect of experimental diabetes mellitus and arthritis on the pharmacokinetics of hydroxychloroquine enantiomers in rats. Pharm Res 1998 Jun;15(6):897903.

65. Piquette-Miller M, Jamali F. Influence of severity of inflammation on the disposition kinetics of propranolol enantiomers in ketoprofen-treated and untreated adjuvant arthritis. Drug Metab Dispos $1995 \mathrm{Feb}$;23(2):240-5.
66. Guirguis MS, Sattari S, Jamali F. Pharmacokinetics of celecoxib in the presence and absence of interferon-induced acute inflammation in the rat: application of a novel HPLC assay. J Pharm Pharm Sci 2001 Jan-Apr;4(1):1-6.

67. Ilic MZ, Martinac B, Handley CJ. Effects of longterm exposure to glucosamine and mannosamine on aggrecan degradation in articular cartilage. Osteoarthritis Cartilage 2003 Aug;11(8):613-622.

68. Altman RD. Glucosamine therapy for knee osteoarthritis: pharmacokientic considerations. Expert Rev Clin Pharmacol 2009;2(4):359-371. 